Fournal of Medical Genetics (1975). 12, 185-192.

\title{
Dermatoglyphic findings in 54 triple-X females and a review of some general principles applying to the soles in sex chromosome aneuploidy
}

\author{
P. SALDANA-GARCIA \\ The Kennedy-Galton Centre, Harperbury Hospital, Shenley, Radlett, Herts WD7 9HQ
}

Summary. The dermatoglyphic findings from 54 females with XXX sex chromosomes are reported. Sole prints were available for study in 33 cases.

Compared with female controls, an excess of radial loops and arches and a reduced mean for total finger ridge-count were the main peculiarities on the fingers.

On the palms, the absence of pattern in areas I and II, and wider ridges in the $a-b$ interval were characteristics observed. Previous findings by other authors with respect to: (1) zygodactylous tendency in the palms, (2) tendency for the ridge width to increase with the number of sex chromosomes, and (3) greater effect of an extra $\mathrm{X}$ chromosome in pattern size reduction but lesser influence on ridge width than an additional $\mathrm{Y}$ chromosome, were confirmed.

On the soles, pattern intensity was above the control average. There was a significant deficit of proximal loops in area III but an excess of proximal $\hat{V}$ together with triradius $h$. Triradius $p^{\prime \prime}$ and zygodactylous $z^{\prime}$ were also significantly reduced in frequency.

General findings with respect to the soles of patients with $\mathrm{X}, \mathrm{XXX}, \mathrm{XXY}$, and XYY sex chromosomal abnormalities are also reviewed. Discrepancies are apparent and further studies are needed.

Finally, a dictionary (Appendices 1 and 2) is provided which gives the frequencies of the complete pattern configurations on the palms and soles of XXX females.

The dermatoglyphic traits associated with certain types of sex chromosomal aberration are not well established. In the triple- $X$, quadruple- $X$, and double-X-double-Y syndromes, features such as total finger ridge-count, maximal atd angle, and finger pattern frequencies have not been completely investigated while characteristics on the feet have been considered even less. The data available are very scanty and often only general findings, applicable to all these syndromes, can be used. Even so, some of these findings need further study; either they have not been confirmed, eg, the width of the ridges tends to increase with the number of sex chromosomes (Penrose and Loesch, 1967) or they are not in good agreement with results obtained in larger samples. Dermatoglyphic peculiarities ob-

Received 6 August 1974. served in XYY males (Saldaña-Garcia, 1973/1974) and in the Turner and Klinefelter syndromes ( $P$. Saldaña-Garcia, unpublished observations) are not in agreement with Holt's general observation (1968) that the absence of triradius $p$ is characteristic in Turner's syndrome, or with the finding of a significant deficit of $z$ triradii on the soles in all cases of sex chromosome aberration reported by Penrose and Loesch (1970a).

The dermatoglyphic findings on 54 cases with XXX sex chromosomes are discussed. Previous and general findings by other authors (Holt, 1968; Penrose and Loesch, 1970a) concerning the soles of some types of sex chromosomal aberrations are also reviewed. Both fingers and palms could be studied in only 52 cases and soles in 33. In one case finger patterns but not palms could be analysed while in a second only the palms and not the fingers could be 
TABLE I

PERCENTAGE FREOUENCIES OF PATTERN-TYPES ON THE FINGERS OF 52 XXX AND 500 UNRELATED FEMALE CONTROLS

\begin{tabular}{|c|c|c|c|c|c|c|c|c|c|c|c|}
\hline & \multicolumn{5}{|c|}{ Left } & \multicolumn{5}{|c|}{ Right } & \multirow{2}{*}{ Fingers } \\
\hline & $\mathbf{v}$ & iv & iii & ii & $\mathbf{i}$ & $\mathbf{i}$ & ii & iii & iv & $\mathbf{v}$ & \\
\hline $\begin{array}{l}X X X \\
\text { Whorls } \\
\text { Ulnar loops } \\
\text { Radial loops } \\
\text { Arches }\end{array}$ & $\begin{array}{r}17.3 \\
75.0 \\
0.0 \\
7.7\end{array}$ & $\begin{array}{r}38.5 \\
59.6 \\
0.0 \\
1.9\end{array}$ & $\begin{array}{r}13.5 \\
67.3 \\
7.7 \\
11.5\end{array}$ & $\begin{array}{l}21.2 \\
38.5 \\
26.9 \\
13.5\end{array}$ & $\begin{array}{r}25.0 \\
67.3 \\
0.0 \\
7.7\end{array}$ & $\begin{array}{r}38.5 \\
59.6 \\
0.0 \\
1.9\end{array}$ & $\begin{array}{r}26.9 \\
34.6 \\
28.8 \\
9.6\end{array}$ & $\begin{array}{r}19.2 \\
59.6 \\
3.8 \\
17.3\end{array}$ & $\begin{array}{r}40.4 \\
51.9 \\
5.8 \\
1.9\end{array}$ & $\begin{array}{r}11.5 \\
86.5 \\
0.0 \\
1.9\end{array}$ & $\begin{array}{r}25.2 \\
60.0 \\
7.3 \\
7.5\end{array}$ \\
\hline $\begin{array}{l}X X \\
\text { Whorls } \\
\text { Ulnar loops } \\
\text { Radial loops } \\
\text { Arches }\end{array}$ & $\begin{array}{r}10.40 \\
87.00 \\
0.20 \\
2.40\end{array}$ & $\begin{array}{r}32.40 \\
62.00 \\
1.40 \\
4.20\end{array}$ & $\begin{array}{r}15.20 \\
70.00 \\
4.40 \\
10.40\end{array}$ & $\begin{array}{l}29.80 \\
37.00 \\
23.20 \\
10.00\end{array}$ & $\begin{array}{r}24.80 \\
69.80 \\
0.00 \\
5.40\end{array}$ & $\begin{array}{r}33.00 \\
64.00 \\
0.00 \\
3.00\end{array}$ & $\begin{array}{l}32.40 \\
40.40 \\
16.20 \\
11.00\end{array}$ & $\begin{array}{r}11.40 \\
79.00 \\
2.20 \\
7.40\end{array}$ & $\begin{array}{r}39.80 \\
58.20 \\
0.40 \\
1.60\end{array}$ & $\begin{array}{r}10.00 \\
88.40 \\
0.20 \\
1.40\end{array}$ & $\begin{array}{r}23.92 \\
65.58 \\
4.82 \\
5.68\end{array}$ \\
\hline
\end{tabular}

Control Population (after Holt, 1963/1964).

examined. In one case feet patterns only were available. Patterns on palms and soles were classified using the topological methods described by Penrose and Loesch $(1969 ; 1970 \mathrm{~b})$.

\section{Fingers}

Arches and radial loops were more common than in female controls (Holt, 1963/1964) but ulnar loops were less frequent. Total differences in pattern frequency between the affected group and normal females were small. However, when pattern frequency between homologous digits of the left and right hands was compared, differences between groups were better observed. For example, the excess of radial loops occurred mainly on fingers ii and iv of the right hand. The frequency of radial loops on Right iv, in the present sample, was much higher than in normal females and even greater than the value of $4.9 \%$ found by Holt (1963/1964) in female Down's syndrome. No radial loops were found on Left iv. With the exception of Left ii, ulnar loops on each digit had a lower frequency than in female controls. Arches were more common than in normal females but the excess occurred mainly on Left $\mathrm{v}$ and Right iii. However, on certain fingers, particularly Left iv, a deficit was observed. These results are summarized in Table I.

The next feature investigated was the total finger ridge-count. It varied from 0 to 201 ridges. High counts were unusual and the mean total ridge count was $104.94 \pm 6.12$ ridges (Table II). When the mean values of the total finger ridge-count between control and triple $\mathrm{X}$ females were compared, the differences between their means, 22 ridges was significant (3.5 times its standard error) and double that observed between control males (145, see Holt, 1963) and XYY (135, see Saldaña-Garcia, 1973/1974). This finding suggested that the addi-
TABLE II

MEANS AND STANDARD DEVIATIONS FOR TOTAL RIDGE-COUNT (TRC) IN XXX AND FEMALE CONTROLS

\begin{tabular}{l|c|c|c}
\hline & No. of Cases & Mean TRC & SD \\
\hline XXX & 52 & $104.94 \pm 6.12$ & 44.14 \\
XX & 825 & $126.97 \pm 1.82$ & 52.33 \\
\hline
\end{tabular}

Control population (after Holt, 1963/1964).

tional X chromosome not only reduced the size of the finger patterns but also had a greater effect on this character than an additional $Y$ chromosome. This was in agreement with the general observation that pattern size is reduced when the number of sex chromosomes is increased (Penrose, 1967; 1968) and with the finding (Penrose, 1968) that an X chromosome has approximately twice the effect on pattern size reduction of an $\mathrm{Y}$ chromosome.

In order to find out if the observed reduction of finger pattern size occurred with a similar intensity on all the fingers of the affected group the mean ridge count on separate digits was ascertained (Table III).

TABLE III

MEAN RIDGE-COUNT (RC) ON SEPARATE FINGERS IN XXX AND FEMALE CONTROLS

\begin{tabular}{|c|c|c|c|c|c|}
\hline & \multicolumn{2}{|c|}{$X X(n=825)$} & \multicolumn{2}{|c|}{$\mathrm{XXX}(\mathrm{n}=52)$} & \multirow{2}{*}{$\begin{array}{c}\text { Difference } \\
\text { in Means } \\
(\mathbf{X X}-\mathbf{X X X})\end{array}$} \\
\hline & Mean RC & SD & Mean RC & SD & \\
\hline $\begin{array}{l}\text { Left v } \\
\text { Left iv } \\
\text { Left iii } \\
\text { Left ii } \\
\text { Left i }\end{array}$ & $\begin{array}{r}12.07 \pm 0.20 \\
14.71 \pm 0.25 \\
10.60 \pm 0.24 \\
9.77 \pm 0.24 \\
14.30 \pm 0.22\end{array}$ & $\begin{array}{l}5.77 \\
7.13 \\
6.76 \\
7.03 \\
6.37\end{array}$ & $\begin{array}{r}8.46 \pm 0.64 \\
12.50 \pm 0.91 \\
9.90 \pm 0.90 \\
8.52 \pm 0.91 \\
11.73 \pm 0.78\end{array}$ & $\begin{array}{l}4.63 \\
6.59 \\
6.46 \\
6.54 \\
5.66\end{array}$ & $\begin{array}{l}+3.61 \pm 0.67 \\
+2.21 \pm 0.94 \\
+0.70 \pm 0.93 \\
+1.25 \pm 0.94 \\
+2.57 \pm 0.81\end{array}$ \\
\hline $\begin{array}{l}\text { Right i } \\
\text { Right ii } \\
\text { Right iii } \\
\text { Right iv } \\
\text { Right v }\end{array}$ & $\begin{array}{l}16.50 \pm 0.23 \\
10.68 \pm 0.25 \\
10.82 \pm 0.22 \\
15.16 \pm 0.24 \\
12.36 \pm 0.21\end{array}$ & $\begin{array}{l}6.49 \\
7.23 \\
6.23 \\
6.78 \\
5.95\end{array}$ & $\begin{array}{r}13.71 \pm 0.79 \\
8.56 \pm 0.92 \\
8.90 \pm 0.86 \\
13.35 \pm 0.84 \\
9.31 \pm 0.66\end{array}$ & $\begin{array}{l}5.71 \\
6.65 \\
6.20 \\
6.03 \\
4.77\end{array}$ & $\begin{array}{l}+2.79 \pm 0.82 \\
+2.12 \pm 0.95 \\
+1.92 \pm 0.88 \\
+1.81 \pm 0.87 \\
+3.05 \pm 0.69\end{array}$ \\
\hline
\end{tabular}

Control population (after Holt, 1968) 
TABLE IV

MEANS FOR $a-b$ RIDGE-COUNT AND $a-b$ DISTANCE IN XXX FEMALES AND 100 FEMALE CONTROLS

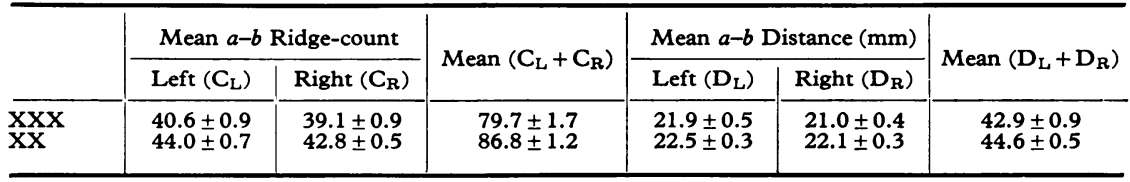

Control population (P. Saldaña-Garcia, unpublished observations).

Reduction of finger pattern size was mainly observed on fingers $\mathrm{v}$ and $\mathrm{i}$ of both the left and right hands. Bimanual differences were also noted, not only between the fingers of the triple $\mathrm{X}$ females but also between them and female controls when homologous digits of left and right hands were compared.

\section{Palms}

The $a-b$ ridge-count and $a-b$ distance (ie, the number of ridges and the distance, measured in $\mathrm{mm}$, between digital triradii $a$ and $b$ ) of the left and right hands of the affected group were considered. As the $a-b$ distance is influenced by age the sample was divided into four age groups: (1) 0-4 years; (2) 5-9 years; (3) 10-14 years; and (4) 15 years and more. The adult sample of the affected group was compared with an adult control sample (Table IV).

As in the general population, the mean $a-b$ ridgecount on the right hand was lower than on the left hand. The mean distance and mean ridge-count in the left and right $a-b$ intervals were, however, lower in the affected group than in female controls. Differences in mean $a-b$ distance between the two groups were small, $0.60 \mathrm{~mm}$ on the left and $1.10 \mathrm{~mm}$ on the right hand, but the mean $a-b$ ridge-count in each interval was approximately 3.5 ridges lower in the XXX group than in female controls. The difference between the mean of the sums of the $a-b$ ridge-counts on the left and right hands $\left(C_{L}+C_{R}\right)$ in triple $\mathrm{X}$ females and the control group was significant (3.4 times its standard error).

The ridge width in the $a-b$ interval was the next trait ascertained. This was done using the method described by Penrose and Loesch (1967). The values obtained for the mean ridge width in each of the groups into which the abnormal sample was divided are shown in Table V. Only the adult sample was compared with a corresponding control sample.

The mean ridge width in the affected group (527) was greater than in normal females (504) and the difference between their means, $23 \mu \mathrm{m}$, was significant (2.86 times its standard error). The value found for the mean ridge width was similar to that
TABLE V

MEANS AND STANDARD DEVIATIONS OF THE RIDGE WIDTH IN XXX AND FEMALE CONTROLS

\begin{tabular}{|c|c|c|c|}
\hline No. of Cases & Age (yr) & $\underset{(\mu \mathrm{m})}{\text { Mean Ridge Width }}$ & SD \\
\hline $\begin{array}{c}X X X \\
8 \\
0 \\
2 \\
42\end{array}$ & $\begin{array}{l}0-4 \\
5-9 \\
10-14 \\
15 \text { and over }\end{array}$ & $\begin{array}{c}319.50 \pm 19.23 \\
481.50 \pm 13.12 \\
527.10 \pm 6.73\end{array}$ & $\begin{array}{l}54.22 \\
18.50 \\
43.58\end{array}$ \\
\hline $\begin{array}{l}X X \\
100\end{array}$ & 15 and over & $504.19 \pm 4.35$ & 43.53 \\
\hline
\end{tabular}

Control population (P. Saldaña-Garcia, unpublished observations).

(528) found by Penrose and Loesch in 1967. The finding agrees with their observation that ridge width increases with the number of sex chromosomes and confirms their suggestion that the $\mathrm{Y}$ chromosome has a greater effect on this character than an additional $X$. The difference between the means for $\mathrm{XYY}$ and $\mathrm{XY}$ was $34 \mu \mathrm{m}$ (SaldañaGarcia, 1973/1974) while that between the means for XXX and XX was $23 \mu \mathrm{m}$.

Another trait influenced by age and also investigated was the maximal atd angle. The value obtained for the mean of the sums of the angles on left and right hands in the adult sample of triple $\mathrm{X}$ females (89.6) was greater than in control females

TABLE VI

MEANS AND STANDARD DEVIATIONS OF SUMS OF LEFT AND RIGHT MAXIMAL atd ANGLES IN XXX AND FEMALE CONTROLS

\begin{tabular}{|c|c|c|c|}
\hline No. of Cases & Age (yr) & $\begin{array}{c}\text { Mean Maximal atd } \\
\text { Angle }\end{array}$ & SD \\
\hline $\begin{array}{c}X X X \\
8 \\
0 \\
2 \\
42 \\
\end{array}$ & $\begin{array}{l}0-4 \\
5-9 \\
10-14 \\
15 \text { and over }\end{array}$ & $\begin{array}{r}105.56 \pm 4.91 \\
83.25 \pm 0.18 \\
89.63 \pm 2.96\end{array}$ & $\begin{array}{r}13.86 \\
0.25 \\
19.17\end{array}$ \\
\hline $\begin{array}{r}X X \\
32 \\
486 \\
507\end{array}$ & $\begin{array}{l}0-4 \\
5-14 \\
15 \text { and over }\end{array}$ & $\begin{array}{l}97.5 \\
89.8 \\
85.9\end{array}$ & $\begin{array}{l}19.6 \\
17.5 \\
15.7\end{array}$ \\
\hline
\end{tabular}

Control population (after Penrose, 1954/1955). 
(85.9) but lower than that found in Turner's syndrome (105.2; Holt, 1968). The difference between the means of the affected group and normal females was small but the finding agreed with the observation that dermoglyphic features in multiple $\mathrm{X}$ cases tend to be the inverse of those found in single $\mathrm{X}$ females. The results obtained are summarized in Table VI.

It must be noted that the value obtained for the mean in the group 10-14 years (83.2) was lower than that in the adult sample. An opposite finding was expected since the hand grows more in length than in breadth with increasing age. However, this unexpected value was considered of little validity as only two individuals contributed to this group.

Finally, the pattern frequencies in the different areas of the palm were ascertained and the results are presented in Table VII.

When comparisons between triple $\mathrm{X}$ females and normal females were made the absence of pattern on areas I and II was a peculiarity observed in the abnormal group. On the hypothenar area the central loop $\hat{\mathrm{H}}$ was reduced in frequency together with triradius $t^{\mathrm{b}}$. An opposite tendency was shown by peripheral loops III and IV, although their frequency was slightly greater than that in normal females. Zygodactyly was also increased. In the abnormal group the triradius $z^{\prime}$ was more common than $z^{\prime \prime}$ and its frequency was more than double that observed in control females. A similar peculiarity was observed in XYY males (Saldaña-Garcia, 1973/ 1974). The finding again confirmed the observation that zygodactyly on the palms seems to be more frequent in all sex chromosomal aberrations (Penrose and Loesch, 1970b).

\section{Soles}

The mean number of loops per sole in the abnormal group was 2.67 which was greater than the value of 2.54 found in female controls (Penrose and Loesch, 1970a). The result was contrary to the deficit of pattern found in triple $\mathrm{X}$ females by the same authors (1970a) when they studied a sample of 44 soles, which gave a mean value of 2.25 . The disagreement between the value found here and theirs might be explained by the greater number of cases considered in this report. It must be noted, however, that the finding of Penrose and Loesch (1970a) of a decrease in pattern intensity on the soles of cases with an increased number of sex chromosomes does not seem to be supported by data from larger samples. A similar finding to that obtained in triple $\mathrm{X}$ females was reported in XYY males (Saldaña-Garcia, 1973/1974) when a larger sample was also considered.

Differences in pattern frequency between the affected group and normal females were also observed (Table VIII).

TABLE VII

FREQUENCIES OF PATTERN-TYPES ON THE PALMS OF 52 XXX FEMALES AND 250 UNRELATED FEMALE CONTROLS

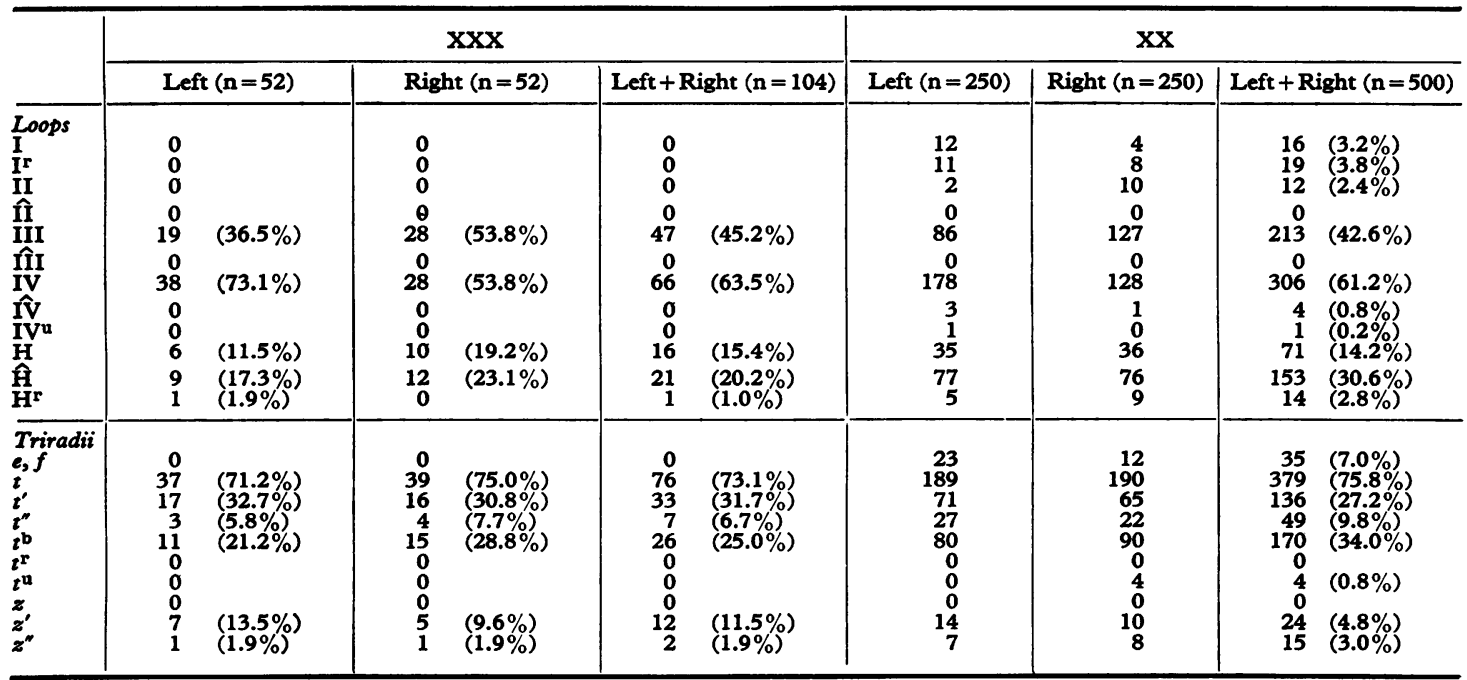

Control population (after Penrose and Loesch, 1970b). 
TABLE VIII

FREQUENCIES OF PATTERN-TYPES ON THE SOLES OF 33 XXX FEMALES AND 150 UNRELATED FEMALE CONTROLS

\begin{tabular}{|c|c|c|c|c|c|c|c|c|c|c|}
\hline & \multicolumn{6}{|c|}{$\mathbf{X X X}$} & \multicolumn{4}{|c|}{$\mathbf{X X}$} \\
\hline & \multicolumn{2}{|c|}{ Left $(n=33)$} & \multicolumn{2}{|c|}{ Right ( $n=33$ ) } & \multicolumn{2}{|c|}{ Left + Right $(n=66)$} & \multirow{2}{*}{$\begin{array}{c}\text { Left }(n=150) \\
127\end{array}$} & \multirow{2}{*}{$\begin{array}{c}\text { Right }(n=150) \\
130\end{array}$} & \multicolumn{2}{|c|}{ Left + Right $(n=300)$} \\
\hline $\begin{array}{l}\text { Loops } \\
\text { I }\end{array}$ & & $(72.7 \%)$ & 24 & $(72.7 \%)$ & 48 & $(72.7 \%)$ & & & 257 & $(86 \%)$ \\
\hline $\begin{array}{l}\text { I } \\
\text { If } \\
\text { II }\end{array}$ & $\begin{array}{r}11 \\
0 \\
5\end{array}$ & $\begin{array}{l}(33.3 \%) \\
(15.2 \%)\end{array}$ & $\begin{array}{l}8 \\
1 \\
6\end{array}$ & $\begin{array}{l}(24.2 \%) \\
(3.0 \%) \\
(18.2 \%)\end{array}$ & $\begin{array}{r}19 \\
1 \\
11\end{array}$ & $\begin{array}{l}(28.8 \%) \\
(1.5 \%) \\
(16.7 \%)\end{array}$ & $\begin{array}{r}53 \\
2 \\
15\end{array}$ & $\begin{array}{r}45 \\
0 \\
16\end{array}$ & $\begin{array}{r}98 \\
2 \\
31\end{array}$ & $\begin{array}{l}(33 \%) \\
(1 \%) \\
(10 \%)\end{array}$ \\
\hline $\begin{array}{l}\text { II } \\
\text { III }\end{array}$ & $\begin{array}{r}9 \\
21\end{array}$ & $\begin{array}{l}(27.3 \%) \\
(63.6 \%)\end{array}$ & $\begin{array}{l}10 \\
19\end{array}$ & $\begin{array}{l}(30.3 \%) \\
(57.6 \%)\end{array}$ & $\begin{array}{l}19 \\
40\end{array}$ & $\begin{array}{l}(28.8 \%) \\
(60.6 \%)\end{array}$ & $\begin{array}{l}30 \\
78\end{array}$ & $\begin{array}{l}39 \\
95\end{array}$ & $\begin{array}{r}69 \\
173\end{array}$ & $\begin{array}{l}(23 \%) \\
(58 \%)\end{array}$ \\
\hline ÎII & & $\begin{array}{l}(3.0 \%) \\
(12.1 \%)\end{array}$ & $\begin{array}{l}2 \\
4\end{array}$ & $\begin{array}{l}(6.1 \%) \\
(12.1 \%)\end{array}$ & $\begin{array}{l}3 \\
8\end{array}$ & $\begin{array}{l}(4.5 \%) \\
(12.1 \%)\end{array}$ & $\begin{array}{l}25 \\
29\end{array}$ & $\begin{array}{l}23 \\
29\end{array}$ & $\begin{array}{l}48 \\
58\end{array}$ & $\begin{array}{l}(16 \%) \\
(19 \%)\end{array}$ \\
\hline IV & 1 & $(3.0 \%)$ & 0 & & 1 & $(1.5 \%)$ & 2 & 3 & 5 & $(2 \%)$ \\
\hline$\widehat{\mathbf{V}}$ & & $(30.3 \%)$ & 16 & $(48.5 \%)$ & 26 & $(39.4 \%)$ & 9 & 11 & 20 & $(7 \%)$ \\
\hline $\begin{array}{l}\text { Triradii } \\
e \\
f \\
g \\
h \\
p \\
p^{\prime} \\
p^{\prime \prime} \\
z \\
z^{\prime} \\
z^{\prime \prime}\end{array}$ & $\begin{array}{r}13 \\
26 \\
1 \\
10 \\
13 \\
9 \\
3 \\
12 \\
1 \\
0\end{array}$ & $\begin{array}{l}(39.4 \%) \\
(78.8 \%) \\
(3.0 \%) \\
(30.3 \%) \\
(39.4 \%) \\
(27.3 \%) \\
(9.1 \%) \\
(36.4 \%) \\
(3.0 \%)\end{array}$ & $\begin{array}{r}11 \\
26 \\
0 \\
16 \\
16 \\
8 \\
1 \\
13 \\
1 \\
0\end{array}$ & $\begin{array}{l}(33.3 \%) \\
(78.8 \%) \\
(48.5 \%) \\
(48.5 \%) \\
(24.2 \%) \\
(3.0 \%) \\
(39.4 \%) \\
(3.0 \%)\end{array}$ & $\begin{array}{r}24 \\
52 \\
1 \\
26 \\
29 \\
17 \\
4 \\
25 \\
2 \\
0\end{array}$ & $\begin{array}{l}(36.4 \%) \\
(78.8 \%) \\
(1.5 \%) \\
(39.4 \%) \\
(43.9 \%) \\
(25.8 \%) \\
(6.1 \%) \\
(37.9 \%) \\
(3.0 \%)\end{array}$ & $\begin{array}{r}61 \\
133 \\
0 \\
9 \\
46 \\
51 \\
12 \\
55 \\
26 \\
3\end{array}$ & $\begin{array}{r}49 \\
135 \\
1 \\
11 \\
58 \\
47 \\
26 \\
56 \\
20 \\
4\end{array}$ & $\begin{array}{r}110 \\
268 \\
1 \\
20 \\
104 \\
98 \\
38 \\
111 \\
46 \\
7\end{array}$ & $\begin{array}{l}(37 \%) \\
(89 \%) \\
(0 \%) \\
(7 \%) \\
(35 \%) \\
(33 \%) \\
(13 \%) \\
(37 \%) \\
(15 \%) \\
(2 \%)\end{array}$ \\
\hline
\end{tabular}

Control population (after Penrose and Loesch, 1970a).

As compared with female controls, loops in area I were reduced in frequency. There was also a deficit of distal IV and particularly of proximal III. An opposite tendency was shown by loops II, $\hat{I I}$, and especially by proximal $\hat{\mathrm{V}}$, while distal III was as common as in the control group. In association with these differences, triradius $f$ was less frequent than in normal females but the number of $e$ triradii was normal. A deficit of the $e$ triradius could be expected because of its association with proximal I. However, the presence of an open field pattern with triradius $e$ on the hallucal area of some soles of the abnormal group explained the finding. Of the $p$ triradii, $p$ was more common than in normals but $p^{\prime}$ and $p^{\prime \prime}$ were less frequent. Zygodactyly was not uncommon. It occurred chiefly between toes ii and iii and the frequency of triradius $z$ was similar to that found in female controls. Triradius $z^{\prime}$ was, however, diminished in frequency while zygodactylous $z^{\prime \prime}$ was not found in the present sample.

In order to detect if any of the differences in pattern frequency between $\mathrm{XXX}$ and $\mathrm{XX}$ females were statistically significant, the mean number of loops and triradii with their standard errors were determined. The method was that described in Saldaña-Garcia (1973/1974) and the results obtained for both groups are shown in Table IX.

A real deficit of proximal loops in area III $(p<$ $0.01)$ and a substantial increase of proximal $\hat{\mathrm{V}}(\mathrm{p}<$
TABLE IX

MEAN NUMBER OF LOOPS AND TRIRADII ON THE SOLES OF XXX AND DIFFERENCE IN MEANS BETWEEN XXX AND XX FEMALES

\begin{tabular}{l|c|c}
\hline & $\begin{array}{c}\text { XXX } \\
\text { (mean number of loops) }\end{array}$ & $\begin{array}{c}\text { Difference in means } \\
(\mathrm{XXX}-\mathrm{XX})\end{array}$ \\
\hline Loops & $1.45 \pm 0.13$ & $-0.27 \pm 0.14$ \\
I & $0.58 \pm 0.13$ & $-0.08 \pm 0.15$ \\
II & $0.33 \pm 0.12$ & $+0.13 \pm 0.13$ \\
$\hat{\text { II }}$ & $0.58 \pm 0.13$ & $+0.12 \pm 0.14$ \\
$\hat{\text { III }}$ & $0.09 \pm 0.05$ & $-0.23 \pm 0.05 \dagger$ \\
IV & $0.24 \pm 0.10$ & $-0.14 \pm 0.11$ \\
$\hat{\mathrm{V}}$ & $0.79 \pm 0.15$ & $+0.65 \pm 0.17 \dagger$ \\
\hline Triradii & & \\
$f$ & $1.58 \pm 0.12$ & $-0.20 \pm 0.13$ \\
$h$ & $0.79 \pm 0.15$ & $+0.65 \pm 0.17 \dagger$ \\
$p^{\prime}$ & $0.88 \pm 0.15$ & $+0.18 \pm 0.17$ \\
$p^{\prime}$ & $0.52 \pm 0.14$ & $-0.14 \pm 0.16$ \\
$p^{\prime \prime}$ & $0.12 \pm 0.05$ & $-0.14 \pm 0.06 *$ \\
$z^{\prime}$ & $0.06 \pm 0.06$ & $-0.24 \pm 0.06 \dagger$ \\
\hline
\end{tabular}

* Significant difference $(p<0.05)$.

+ Significant difference $(\mathrm{p}<0.01)$

$0.01)$ were peculiarities observed. There was also a strong suggestion of a real deficit of distal I together with the $f$ triradius. Triradii $h$ were increased in frequency $(\mathrm{p}<0.01)$ but $p^{\prime \prime}(\mathrm{p}<0.05)$ and, particularly, $z^{\prime}(\mathrm{p}<0.01)$ showed a reduction in frequency.

It must be mentioned that the value for the significance of proximal $\hat{\mathrm{V}}$ and the $h$ triradius may be less reliable than those obtained for other patterns. 
This results from the fact that the proximal loop $\hat{V}$ and corresponding $h$ triradius in the control data may not always have been printed (Penrose and Loesch, 1970a).

\section{General principles}

The data (Table $\mathrm{X}$ ) obtained from triple $\mathrm{X}$ females together with those from studies on XYY males (Saldaña-Garcia, 1973/1974) and cases of Turner's and Klinefelter's syndrome (P. SaldañaGarcia, unpublished observation) enabled certain findings applicable to the soles of some types of sex chromosomal abnormalities to be reconsidered.

TABLE $\mathrm{X}$

MEAN NUMBER OF LOOPS PER SOLE (PATTERN INTENSITY) AND FREQUENCY OF $p, z, z^{\prime}$, AND $z^{*}$ TRIRADII IN SOME SEX CHROMOÓSÖMAL ABERRATIONS AND IN CONTROL MALES AND FEMALES

\begin{tabular}{|c|c|c|c|c|c|c|}
\hline & $\mathbf{X}$ & $\mathbf{x x}$ & $\mathbf{X X X}$ & $\mathbf{X Y}$ & $\mathbf{X X Y}$ & $\mathbf{X Y Y}$ \\
\hline Pattern intensity & 2.85 & 2.54 & 2.67 & 2.72 & 2.66 & 2.98 \\
\hline $\begin{array}{l}\text { Triradii (\%) } \\
\boldsymbol{p} \\
\boldsymbol{z} \\
\boldsymbol{z}^{\prime \prime} \\
\boldsymbol{z}^{\prime \prime}\end{array}$ & $\begin{array}{r}33.9 \\
54.8 \\
25.8 \\
8.1\end{array}$ & $\begin{array}{r}35.0 \\
37.0 \\
15.0 \\
2.0\end{array}$ & $\begin{array}{c}43.9 \\
37.9 \\
3.0 \\
0\end{array}$ & $\begin{array}{r}37.0 \\
42.0 \\
18.0 \\
3.0\end{array}$ & $\begin{array}{c}43.5 \\
29.0 \\
1.6 \\
0\end{array}$ & $\begin{array}{r}52.9 \\
47.1 \\
11.8 \\
2.0\end{array}$ \\
\hline $\begin{array}{c}\text { Number of soles } \\
\text { (left + right })\end{array}$ & 62 & 300 & 66 & 300 & 62 & 51 \\
\hline
\end{tabular}

Control population (after Penrose and Loesch, 1970a).

Pattern intensity. In each of the aneuploid states under consideration, with the exception of Klinefelter's syndrome, pattern intensity on the soles was greater than in the appropriate control group (see Table X). The opposite has been observed by Penrose and Loesch (1970a). Even in Klinefelter's syndrome the mean number of loops per sole (2.66) was, in the present sample, similar to the value of 2.72 found in male controls (Penrose and Loesch, 1970a) and the finding contrasted with their observation that pattern intensity on the soles of XXY males (2.07) is significantly reduced (1970a). As the present series contained most of the cases studied by Penrose and Loesch $(1970 \mathrm{a} ; 1$ 1970b), the discrepancy between these values and theirs might be explained by the greater number of cases considered in this report.

Frequency of $p$ triradius. When the percentage of $p$ triradii in each of the abnormal groups was compared with that in its corresponding control sample, an excess of $p$ triradius was a peculiarity observed in most of the aneuploid states under con- sideration (see Table $\mathrm{X}$ ). In Turner's syndrome, however, the frequency of $p$ triradius was slightly lower than in female controls but the difference between them (1.1\%) was insignificant. This finding did not support Holt's observation (1968) that the absence of triradius $p$ is characteristic in Turner's syndrome.

Frequency of $z$ triradii. In Turner's syndrome an excess of $z$ triradii was observed. Increased frequency of $z$ triradii was expected because of the excess of loops III and IV which is found in single $\mathrm{X}$ females. The finding contrasted with the observation that zygodactyly is remarkably infrequent on the soles of cases with Turner's syndrome in spite of the excess of III loops (Penrose and Loesch, 1970a) but it was in agreement with the topological rules (Penrose and Loesch, 1969) that zygodactylous triradii $z, z^{\prime}$, and $z^{\prime \prime}$ are usually associated with loops $\widehat{\mathrm{II}}, \hat{\mathrm{III}}$, and $\widehat{\mathrm{IV}}$.

In XXX females, triradius $z$ was as common as in female controls, $z^{\prime}$ was reduced in frequency but $z^{\prime \prime}$ was not found in the studied sample. Zygodactyly was decreased in frequency and this supported a similar observation found by Penrose and Loesch (1970a) on 44 soles from triple X females. However, the frequency of triradius $z$ in the general population is much higher than that of triradius $z^{\prime}$ or $z^{\prime \prime}$ (see Table $\mathrm{X}$ ). Triradius $z$ occurred with similar frequency in both the abnormal (37.9\%) and control groups $(37.0 \%)$. Consequently, zygodactyly was not found to be an unusual feature in the affected group but occurred between toes ii and iii. This finding disagreed with the report that a significant deficit of $z$ triradii occurs in all types of sex chromosomal abnormalities (Penrose and Loesch, 1970a).

In Klinefelter's syndrome a deficit of $z$ triradii was observed and zygodactyly was uncommon. A similar peculiarity has been reported by Penrose and Loesch (1970a).

In the case of XYY males, $z$ was more common than in male controls, $z^{\prime}$ was less frequent, but $z^{\prime \prime}$ had almost a similar frequency to that in the control group (see Table $\mathbf{X}$ ). This contradicted the deficit of $z$ triradii found by Penrose and Loesch (1970a) as the only significant anomaly in a sample of 44 soles from XYY cases.

I express my gratitude to those colleagues who have sent prints to The Kennedy-Galton Centre which have made this study possible. I am indebted to Miss Helen Lang Brown for her help during the preparation of this paper and Mr M. A. C. Ridler for reading the typescript and giving constructive criticism. 


\section{REFBRENCES}

Holt, S. B. (1963). Current advances in our knowledge of the inheritance of variations in finger-prints. In Proceedings of the Second International Congress of Human Genetics (Rome, 1961) vol. 3, p. 1450. Istituto G. Mendel, Rome.

Holt, S. B. (1963/1964). Finger-print patterns in mongolism. Annals of Human Genetics, 27, 279-282.

Holt, S. B. (1968). The Genetics of Dermal Ridges. Thomas, Springfield, Illinois.

Penrose, L. S. (1954/1955). The distal triradius $t$ on the hands of parents and sibs of mongol imbeciles. Annals of Human Genetics, 19, 10-38.

Penrose, L. S. (1967). Finger-print pattern and the sex chromosomes. Lancet, 1, 298-300.
Penrose, L. S. (1968). Medical significance of finger-prints and related phenomena. British Medical fournal, 2, 321-325.

Penrose, L. S. and Loesch, D. (1967). A study of dermal ridge width in the second (palmar) interdigital area with special reference to aneuploid states. Fournal of Mental Deficiency Research, 11, 36-42.

Penrose, L. S. and Loesch, D. (1969). Dermatoglyphic sole patterns: a new attempt at classification. Human Biology, 41, 427448.

Penrose, L. S. and Loesch, D. (1970a). Comparative study of sole patterns in chromosomal abnormalities. Fournal of Mental Deficiency Research, 14, 129-140.

Penrose, L. S. and Loesch, D. (1970b). Topological classification of palmar dermatoglyphics. Fournal of Mental Deficiency Research, 14, 111-128.

Saldaña-Garcia, P. (1973/1974). A dermatoglyphic study of sixtyfour XYY males. Annals of Human Genetics, 37, 107-116.

\section{Appendix 1}

\section{DERMATOGLYPHIC DICTIONARY OF XXX FEMALES (104 PALMS)}

\begin{tabular}{|c|c|c|c|c|c|c|c|c|c|c|c|c|c|c|c|c|c|c|c|c|c|c|c|}
\hline \multicolumn{10}{|c|}{ Loops } & \multicolumn{10}{|c|}{ Triradii } & \multicolumn{4}{|c|}{ Incidence* } \\
\hline I & $I^{r}$ & II & III & IV & $\hat{I V}$ & IVu & $\mathbf{H}$ & $\hat{\mathbf{H}}$ & $\mathrm{H}^{\mathrm{r}}$ & $e$ & $f$ & $t$ & $t^{\prime}$ & $t^{\prime \prime}$ & $t^{\mathrm{b}}$ & $t^{\mathrm{r}}$ & $t^{\mathrm{u}}$ & $z$ & $z^{\prime} z^{\prime \prime}$ & D & L & $\mathbf{R}$ & $T$ \\
\hline- & - & - & 1 & - & - & - & - & - & - & - & - & 1 & - & - & - & - & - & - & -- & 4 & 4 & 6 & 10 \\
\hline - & - & - & 1 & - & - & - & - & - & - & - & - & - & 1 & - & - & - & - & - & - & 4 & 3 & 9 & 12 \\
\hline - & - & - & 1 & 2 & - & - & - & - & - & - & - & 1 & - & - & - & - & - & - & $-\quad-$ & 6 & 1 & 0 & 1 \\
\hline - & - & - & 1 & 1 & - & - & - & - & - & - & - & 1 & - & - & - & - & - & - & $-\quad-$ & 5 & 1 & 1 & 2 \\
\hline- & - & - & 1 & 1 & - & - & - & - & - & - & - & - & 1 & - & - & - & - & - & $-\quad-$ & 5 & 3 & 1 & 4 \\
\hline - & - & - & 1 & 1 & - & - & - & - & - & - & - & - & - & - & 1 & - & - & - & - & 5 & 0 & $\begin{array}{l}1 \\
1\end{array}$ & $\begin{array}{l}4 \\
1\end{array}$ \\
\hline - & - & - & 1 & 1 & - & - & 1 & - & - & - & - & 1 & 1 & - & - & - & - & - & -- & 5 & 0 & 1 & 1 \\
\hline - & - & - & 1 & 1 & - & - & 1 & 1 & - & - & - & 1 & 1 & - & 1 & - & - & - & $-\quad-$ & 5 & 0 & 1 & 1 \\
\hline - & - & - & 1 & 1 & - & - & - & 1 & - & - & - & 2 & - & - & - & - & - & - & $-\quad-$ & 5 & 0 & 1 & 1 \\
\hline - & - & - & 1 & 1 & - & - & - & 1 & - & - & - & 1 & - & - & 1 & - & - & - & - - & 5 & 1 & 3 & 4 \\
\hline - & - & - & 1 & 1 & - & - & - & 1 & - & - & - & - & 1 & - & 1 & - & - & - & $-\quad-$ & 5 & 1 & 0 & 1 \\
\hline - & - & - & 1 & - & - & - & 1 & - & - & - & - & 1 & 1 & - & - & - & - & - & $-\quad-$ & 4 & 2 & 1 & 3 \\
\hline - & - & - & 1 & - & - & - & $\hat{1}$ & - & - & - & - & 1 & - & 1 & - & - & - & - & $-\quad-$ & 4 & 1 & 1 & 2 \\
\hline- & - & - & 1 & - & - & - & 1 & 1 & - & - & - & 1 & 1 & - & 1 & - & - & - & & $\begin{array}{l}4 \\
4\end{array}$ & 0 & 1 & 1 \\
\hline - & - & - & 1 & - & - & - & - & 1 & - & - & - & 1 & - & - & 1 & - & - & - & - & 4 & 2 & 1 & 3 \\
\hline - & - & - & - & 2 & - & - & - & - & - & - & - & 1 & - & - & - & - & - & - & $-\quad-$ & 5 & 2 & 1 & 3 \\
\hline - & - & - & - & 1 & - & - & - & - & - & - & - & 1 & - & - & - & - & - & - & $-\quad-$ & 4 & 14 & 8 & 22 \\
\hline - & - & - & - & 1 & - & - & - & - & - & - & - & 1 & - & - & - & - & - & - & $1-$ & 3 & 1 & 0 & 1 \\
\hline - & - & - & - & 1 & - & - & - & - & - & - & - & - & 1 & - & - & - & - & - & $-\quad-$ & 4 & 1 & 0 & 1 \\
\hline - & - & - & - & i & - & - & - & - & - & - & - & - & - & - & 1 & - & - & - & $-\quad-$ & 4 & 0 & 2 & 2 \\
\hline - & - & - & - & 1 & - & - & 1 & - & - & - & - & 1 & 1 & - & - & - & - & - & $-\quad-$ & 4 & 1 & 0 & 1 \\
\hline- & - & $=$ & - & 1 & $=$ & $=$ & 1 & - & - & $=$ & $\overline{-}$ & 1 & $\frac{1}{-}$ & $\overline{1}$ & E & $\overline{-}$ & $\overline{-}$ & $\overline{-}$ & & $\begin{array}{l}4 \\
4\end{array}$ & 0 & $\begin{array}{l}0 \\
1\end{array}$ & 1 \\
\hline - & - & - & - & 1 & - & - & 1 & - & - & - & - & 1 & - & - & 1 & - & - & - & & $\begin{array}{l}4 \\
4\end{array}$ & 1 & 1 & $\frac{1}{2}$ \\
\hline 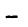 & - & - & - & 1 & - & - & 1 & - & - & - & - & - & $\overline{1}$ & $\overline{1}$ & - & $\overline{-}$ & - & - & $=-$ & $\begin{array}{l}4 \\
4\end{array}$ & $\begin{array}{l}1 \\
0\end{array}$ & 1 & 2 \\
\hline - & - & - & - & 2 & - & - & 1 & 1 & - & - & - & 1 & i & - & 1 & - & - & - & $-\quad-$ & 5 & 1 & 0 & 1 \\
\hline- & - & - & - & 2 & - & - & - & 1 & - & - & - & - & 1 & - & 1 & - & - & - & - - & 5 & 1 & 0 & 1 \\
\hline - & - & - & - & 1 & - & - & - & i & - & - & - & 1 & - & - & 1 & - & - & - & & 4 & 2 & 4 & 6 \\
\hline - & - & - & - & 1 & - & - & - & 1 & - & - & - & - & 1 & - & 1 & - & - & - & - & 4 & 1 & 0 & 1 \\
\hline - & - & - & - & 1 & - & - & - & - & 1 & - & - & - & - & 1 & 1 & - & - & - & - & 4 & 1 & 0 & 1 \\
\hline - & - & - & - & - & - & - & 1 & - & - & - & - & 1 & - & 1 & - & - & $=$ & - & $1-$ & $\begin{array}{l}4 \\
2\end{array}$ & 0 & 1 & 1 \\
\hline - & - & - & - & - & 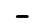 & - & 1 & 1 & - & - & - & 1 & 1 & - & 1 & - & - & - & $1-$ & 2 & 0 & 1 & 1 \\
\hline - & - & - & - & - & - & - & - & 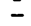 & - & - & - & 1 & - & - & 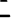 & - & - & - & $1-$ & 2 & 2 & 3 & 5 \\
\hline - & - & - & - & - & - & - & - & - & - & - & - & 1 & - & - & - & - & - & - & -1 & 2 & 1 & 1 & 2 \\
\hline - & - & - & - & - & - & - & - & - & - & - & - & 2 & 1 & - & 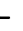 & - & - & - & $1-$ & 2 & 3 & 0 & 3 \\
\hline- & - & - & - & - & - & - & - & - & - & - & - & - & - & 1 & - & - & - & - & 1 & 2 & 1 & 0 & 1 \\
\hline
\end{tabular}

* $D=$ number of unspecified digital triradii; $L=$ left palm; $R=$ right palm; $T=$ total (left + right palms). 


\begin{tabular}{|c|c|c|c|c|c|c|c|c|c|c|c|c|c|c|c|c|c|c|c|c|c|c|}
\hline \multicolumn{11}{|c|}{ Loops } & \multicolumn{8}{|c|}{ Triradii } & \multicolumn{4}{|c|}{ Incidence } \\
\hline I & I & $\mathrm{I}^{\mathrm{s}}$ & II & $\hat{\mathbf{I I}}$ & III & Î̂I & IV & $\hat{\mathbf{I V}}$ & $\mathbf{v}$ & $\hat{\mathbf{v}}$ & & $g$ & $h$ & $p$ & & $p^{\prime \prime} z$ & & $z^{\prime \prime}$ & D & $\mathbf{L}$ & $\mathbf{R}$ & $\mathbf{T}$ \\
\hline $\begin{array}{l} \\
\overline{7} \\
1 \\
1 \\
1 \\
1 \\
1 \\
1 \\
1 \\
1 \\
1 \\
1 \\
1 \\
1\end{array}$ & $\begin{array}{l}\bar{y} \\
\overline{1} \\
1 \\
1 \\
1 \\
1 \\
1 \\
1 \\
1 \\
1 \\
1 \\
\bar{z} \\
\overline{-} \\
\overline{-} \\
\overline{-} \\
\bar{z} \\
\overline{-}\end{array}$ & 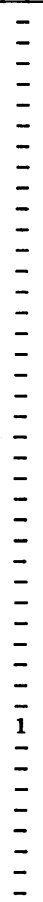 & 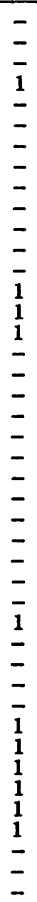 & 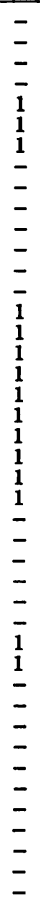 & 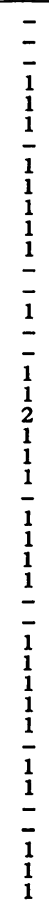 & 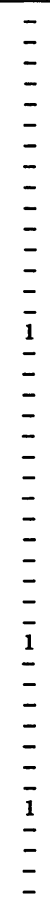 & $\begin{array}{l}\bar{Z} \\
\bar{Z} \\
\overline{1} \\
\bar{Z} \\
\overline{1} \\
1 \\
1 \\
1 \\
\overline{1} \\
\bar{Z} \\
\bar{Z} \\
\bar{Z} \\
\overline{1} \\
1 \\
\overline{1} \\
\bar{Z} \\
\overline{1} \\
\bar{Z} \\
\bar{Z}\end{array}$ & 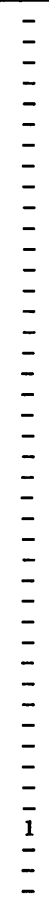 & 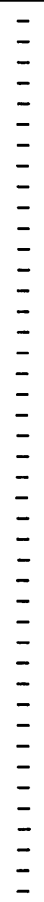 & 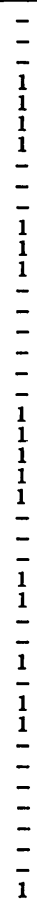 & 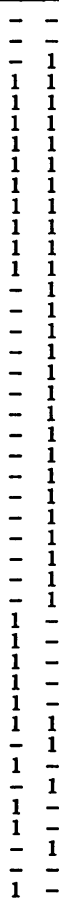 & 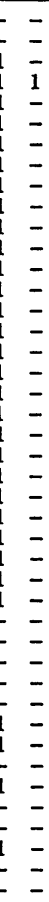 & $\begin{array}{l}\bar{y} \\
\overline{1} \\
1 \\
1 \\
1 \\
\overline{1} \\
\overline{1} \\
1 \\
1 \\
\overline{1} \\
\bar{y} \\
\overline{1} \\
1 \\
1 \\
1 \\
1 \\
\overline{1} \\
1 \\
1 \\
\overline{1} \\
1 \\
1\end{array}$ & $\frac{\overline{1}}{1}$ & 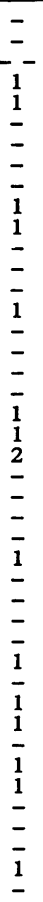 & 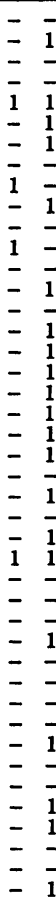 & 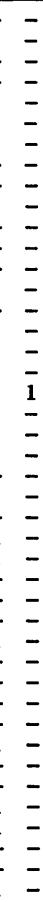 & 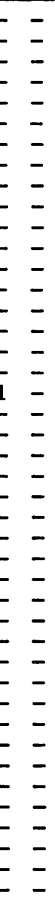 & $\begin{array}{l}04 \\
3 \\
4 \\
4 \\
4 \\
4 \\
4 \\
4 \\
4 \\
4 \\
3 \\
4 \\
4 \\
4 \\
3 \\
5 \\
5 \\
5 \\
4 \\
3\end{array}$ & $\begin{array}{l}9 \\
0\end{array}$ & $\begin{array}{l}9 \\
1 \\
1 \\
2 \\
2 \\
0 \\
0 \\
1 \\
1 \\
1 \\
0 \\
0 \\
0 \\
1\end{array}$ & $\begin{array}{l}1 \\
1 \\
6 \\
1 \\
1 \\
1 \\
1 \\
3 \\
1 \\
1 \\
1 \\
1 \\
2 \\
1 \\
1 \\
1 \\
2 \\
2 \\
1 \\
1 \\
1 \\
2 \\
4 \\
1 \\
1 \\
2 \\
6 \\
1 \\
1 \\
2 \\
1 \\
1\end{array}$ \\
\hline
\end{tabular}

